\title{
Effects of body mass index on cecal intubation time in women
}

Banu Karapolat (D), Üzer Küçüktülü (D)

\begin{tabular}{|c|c|}
\hline \multirow[t]{5}{*}{ ABSTRACT } & $\begin{array}{l}\text { Objective: During colonoscopy, cecal intubation time is prolonged with increase in difficulty of the procedure. Cecal } \\
\text { intubation time may be affected by age, gender, and body structure. We investigated the relationship between body } \\
\text { mass index and cecal intubation time in women. }\end{array}$ \\
\hline & $\begin{array}{l}\text { Material and Methods: This prospective study included } 61 \text { women who underwent colonoscopy in the endoscopy } \\
\text { unit of the General Surgery Clinic in Trabzon Kanuni Training and Research Hospital between January } 2016 \text { and Sep- } \\
\text { tember } 2016 \text {. The colonoscopies were performed by a single surgeon. The height and weight of all the participants } \\
\text { were measured, and their body mass index values were calculated before the procedure. The timer was activated as } \\
\text { soon as entry was made from the anal region with colonoscope and stopped when the cecum was reached. The cecal } \\
\text { intubation time was recorded for each subject. The results were evaluated statistically, and } p<0.05 \text { was considered } \\
\text { to be significant. }\end{array}$ \\
\hline & $\begin{array}{l}\text { Results: The mean body mass index was } 29.6 \pm 6.8 \mathrm{~kg} / \mathrm{m}^{2} \text {. The median cecal intubation time was } 4 \mathrm{~min} \text {. (minimum } \\
2 \mathrm{~min} \text {; maximum } 8 \mathrm{~min}) \text {. A significantly strong positive correlation was found between body mass index and cecal } \\
\text { intubation time }(\mathrm{r}:-0.891, \mathrm{p}<0.001) \text {. }\end{array}$ \\
\hline & $\begin{array}{l}\text { Conclusion: Cecal intubation time was found to be shorter in women whose body mass index values were high. } \\
\text { This outcome may help to eliminate the "the colonoscopy will be difficult" preconception, which is common among } \\
\text { endoscopists with regard to the colonoscopies for obese female patients. }\end{array}$ \\
\hline & Keywords: Body mass index, cecum, colonoscopy, time \\
\hline
\end{tabular}

ORCID IDs of the authors: B.K. 0000-0001-5132-8266; Ü.K. 0000-0003-4481-9176.

Cite this paper as: Karapolat B, Küçüktülü Ü. Effects of body mass index on cecal intubation time in women. Turk J Surg 2018; 34: 94-96.

Clinic of General Surgery, Kanuni Training and Research Hospital, Trabzon, Turkey

\section{Corresponding Author} Banu Karapolat

e-mail: banukarapolat@hotmail. com

Received: 01.12.2016

Accepted: 03.03.2017

CCopyright 2018 by Turkish Surgical Association Available online at www.turkjsurg.com

\section{INTRODUCTION}

Colonoscopy is widely used in the diagnosis of colorectal diseases and in the follow-up of their treatments of $(1,2)$. It is a safe procedure that is usually well tolerated with sedoanalgesia. Colonoscopy is used as a treatment modality in some colon diseases such as colon mucosal bleedings, polyps and luminal stenosis (3). Cecal intubation, an important factor in the evaluation of colonoscopy performance, is necessary to ensure that the colon examination is whole and complete (2). Cecal intubation time (CIT) describes the length of time in which colonoscopy reaches from the anal region to the caecum, and is a determining factor for difficult colonoscopies (4). It is reported in the literature that CIT is affected by advanced age, female gender, abdominal surgical history, diverticulosis, poor intestinal cleansing and by the colonoscopy experience of endoscopist $(3,4)$.

There is a significant relationship between the body structures of the patients and CIT (5). An ideal colonoscopy application and duration can be achieved in cases with optimal body mass index (BMI). Often, low circumference of the waist and little visceral fat tissue cause prolongations in the duration of colonoscopy. However, obese cases that are frequently encountered in everyday practice may pose a problem during colonoscopies for the endoscopists due to inadequate intestinal cleansing as well as phenotypic characteristics. It is also more difficult to perform maneuvers such as the application of abdominal pressure and new positioning during colonoscopy in obese patients, and this situation can lead to prolongation of colonoscopy (5).

The aim of this study is to identify the relationship between BMI and CIT in colonoscopy cases without different variables such as endoscopist's experience, adequacy of bowel cleansing and intraabdominal adhesions.

\section{MATERIAL AND METHODS}

\section{Cases and study protocol}

This study includes 61 female patients in whom colonoscopy was performed in the endoscopy department of General Surgery Clinic in Trabzon Kanuni Training and Research Hospital between January 2016 and September 2016. All of the cases were 18 years of age, and none of them had a history of abdominal 


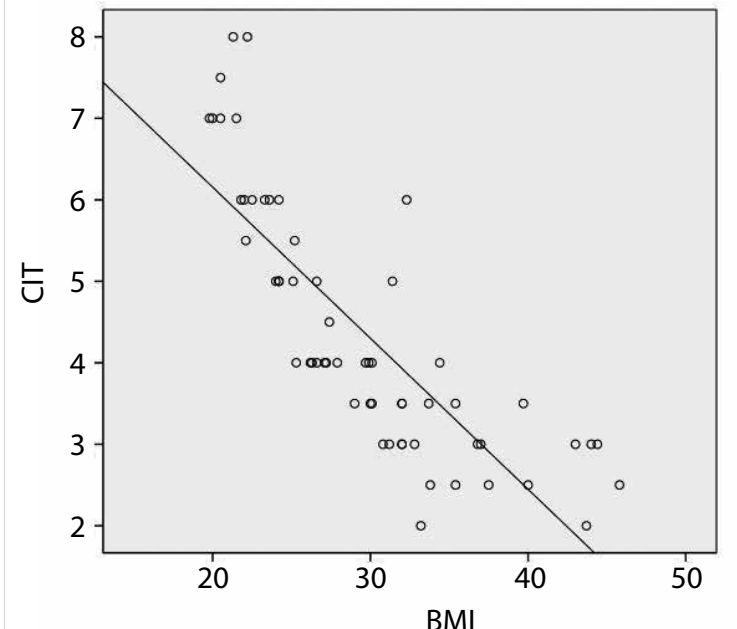

Figure 1. A strong positive correlation was found between $\mathrm{BMI}$ and CIT at a statistically significant level

operation. The most common indications for colonoscopy include constipation, anemia, intermittent inactive rectal bleeding, occult blood positivity in the stool, and polypectomy that was previously performed. Here, the cases who will undergo colonoscopy for therapeutic purposes, the cases with colostomy, the cases who had abdominal operation, the cases who had inadequate intestinal cleansing during the procedure, and the cases who rejected the administration of sedoanalgesia during colonoscopy were excluded from the study. Colonoscopy was performed by a single surgeon. It was suggested that the patients consume liquid food products and water 2 days before the procedure, and the intestinal cleaning was performed by using Sennozid $a+b$ calcium (X-M solution Yenişehir Laboratory Ind. Trade. Co. Ltd., Ankara, Turkey) and BT enema (BT enema, Yenişehir Laboratory Ind. Trade. Co. Ltd., Ankara, Turkey). The patients were told not to eat and drink anything after midnight before the procedure, and they were enabled to come to the clinic hungry in the morning. Weights and heights of all the cases were measured by standard methods before the procedure, and their BMls were calculated. This study protocol was approved by the local ethics committee and all cases were given sufficient verbal information, and they read and signed the written informed consent forms before the procedure. The work was carried out in accordance with the Helsinki Declaration principles, which were revised in 2000.

\section{Colonoscopy procedure}

Colonoscopy procedures were performed between 9.00 and 11.00 in the morning. Prior to colonoscopy, a vascular access was opened with a thick calibrated branule in the antecubital vein, and monitorization was performed for the pulse, blood pressure, arterial and blood oxygen saturations. Two liters/ minute of nasal oxygen was given to all patients during the procedure and all medications were administered intravenously. Initially, midazolam (Dormicum ampoules, Roche, Istanbul, Turkey) was given at a dose of $0.05 \mathrm{mg} / \mathrm{kg}$ and meperidine (Aldol bulbs, Liba, Istanbul, Turkey) was given at a dose of $0.3 \mathrm{mg} / \mathrm{kg}$. When necessary, additional doses were administered by the anesthesiologist according to the follow-up criteria of the case in the treatment process (maximum doses:
$0.1 \mathrm{mg} / \mathrm{kg}$ for midazolam and $1.5 \mathrm{mg} / \mathrm{kg}$ for meperidine). All colonoscopy procedures were performed by a single surgeon with 10 years of colonoscopy experience after the cases received adequate sedation. When the anal region was entered with colonoscopy, the time was started and it was terminated when the caecum was reached. These CITs obtained are recorded for each case.

\section{Statistical Analysis}

All statistical data analyses were made using the SPSS 15.0 version package program for Windows (SPSS Inc., Chicago, IL, USA). Descriptive statistics and Spearman correlation analysis were used here. The statistical significance level was accepted as $p<0.05$. The Spearman correlation analysis was performed to assess the relationship between BMI and CIT.

\section{RESULTS}

All the cases in this study were female. In the investigation of etiology; constipation and rectal bleeding, which are the indications of colonoscopy, were found to be in the first place with the rates of $29 \%$ and $22 \%$, respectively. The youngest patient was 18 years old and the oldest was 81 years old; the mean age was found as $47.7 \pm 14.6$ years. The lowest BMI was $19.8 \mathrm{~kg} /$ $\mathrm{m}^{2}$ and the highest BMI was $45.8 \mathrm{~kg} / \mathrm{m}^{2}$. The mean BMI was $29.6 \pm 6.8 \mathrm{~kg} / \mathrm{m}^{2}$. Colonoscopy was performed successfully in all cases and no complication occurred. The median CIT was 4 min. (minimum $2 \mathrm{~min}$ - maximum $8 \mathrm{~min}$ ). There was a strong positive correlation between BMI and CIT at a statistically significant level $(r:-0.891, p<0.001)$ (Figure 1).

\section{DISCUSSION}

Over the years, the relationship between the body weight and the technical difficulties encountered during colonoscopy has been a matter of serious debate, especially in the stage of reaching the caecum. There are different data in the literature indicating that weak or obese patients cause difficulty for the endoscopist during colonoscopy $(3,4)$. In fact, obesity is considered to be an independent factor that causes difficult and long colonoscopy and is associated with poor intestinal cleansing (5). If CIT is prolonged during the colonoscopy; discomfort, respiratory depression, low oxygen saturation, hypotension, cardiac arrhythmia, aspiration, malignant hyperthermia and allergic reactions may occur. It should be kept in mind that these undesired conditions may depend on the medicines and/or materials used. In addition, rare serious complications related to barotrauma, such as mucosal tears, intestinal perforation and air embolism, may also be seen (6). Therefore, the total length of colonoscopy and the importance of CIT have increased even more in obese cases, potentially bearing the risk of complications.

In this study, a number of limiting variables have been eliminated to evaluate the relationship between the duration of colonoscopy and body weight. For this purpose; the patients in whom colonoscopy would be performed for treatment, the patients with colostomy, the patients who underwent $a b$ dominal or pelvic surgery, the patients with inadequate bowel cleansing during the procedure, the patients who rejected sedoanalgesia during colonoscopy, and the patients in whom colonoscopy was performed by the other endoscopists in our clinic were not included in our study. Thus, a homogeneous 
patient group which completely consisted of female patients and operated by a single endoscopist was used and the external effects were tried to be minimized.

The BMI is a commonly used parameter for defining the body weight. However, BMI does not give a definitive information about the accumulation of fat in the retroperitoneal area and in the abdomen. In fact, these regions with fat accumulation are best displayed with abdominal computed tomography (7). However, it does not seem to be possible to take tomography in all cases in practice, considering both unnecessary radiation exposure and cost (5). For this reason, we preferred to use BMI, which is the most harmless and easiest way to define the body weights of colonoscopy cases included in this study. In the result of our study, a strong positive correlation at a statistically significant level was found between BMI and CIT in women. It was revealed that $\mathrm{CIT}$ was shorter in cases with higher $\mathrm{BMI}$. The results obtained are consistent with the literature $(4,8-10)$. It is known that there is somewhat more fat accumulation in the retroperitoneal area of the women with higher BMI than those with normal BMI. We believe that stored fat pads in this area may cause the colonoscope to move smoothly at sharp curves during the colonoscopy procedure and shorten CIT. At the same time, the fact that overweight patients have relatively shorter colon than the normal population can also provide an additional contribution to the shortening of CIT $(4,11)$.

As a general opinion, endoscopists believe that they may encounter difficulties in the procedures in obese patients and that the duration of endoscopy may be longer than it should be (5). However, in this study, we have obtained data showing that the duration of endoscopy is shorter in obese women than in other cases. In terms of preventing the false beliefs and concerns mentioned above, we think that these results may be important for endoscopists interested in colonoscopy.

In a prospective study conducted by Bernstein et al, it has been reported that extended CITs occur due to the factors such as advanced age, female gender, low BMI, poor intestinal cleansing, and low number of annual cases of endoscopists (12). One of the important factors affecting CIT is the colonoscopy experience of endoscopists $(2,12,13)$. As in many medical applications, endoscopists gain experience with the number of procedures they perform and the difficulties-complications they encounter during the procedure of colonoscopy and with successful control and management of these difficulties. It is therefore evident that CIT averages achieved by an experienced endoscopist during colonoscopy will be much shorter. We think that the CIT of colonoscopies performed by different endoscopists will vary depending on the experience, and this situation can affect the homogeneity of the clinical trial. For this reason, colonoscopies were performed by a single endoscopist in our study and, the factor of endoscopist occurring due to the changing experiences and abilities was eliminated.

This study has a number of limitations such as the fact that it has been performed in one center, the number of cases is low and only female cases have been evaluated. We think that the results obtained here can gain more value in the future with multi-centered studies using larger populations.

\section{CONCLUSION}

Cecal intubation time was found to be shorter in women with higher BMI. This may help eliminate the prejudice of "colonoscopy will be difficult", which is a widespread opinion about colonoscopy in obese female patients.

Ethics Committee Approval: Authors declared that the research was conducted according to the principles of the World Medical Association Declaration of Helsinki "Ethical Principles for Medical Research Involving Human Subjects".

Informed Consent: Written informed consent was obtained from patients who participated in this study.

Peer-review: Externally peer-reviewed.

Author Contributions: Concept - B.K.; Design - B.K., U.K.; Supervision - B.K., U.K.; Resource - B.K.; Materials - B.K., U.K.; Data Collection and/or Processing - B.K.; Analysis and/or Interpretation - B.K., U.K.; Literature Search - B.K.; Writing Manuscript - B.K.; Critical Reviews - B.K., U.K.

Conflict of Interest: The authors have no conflicts of interest to declare.

Financial Disclosure: The authors declared that this study has received no financial support.

\section{REFERENCES}

1. Özsoy M, Celep B, Ersen O, Özkececi T, Bal A, Yılmaz S, et. al. Our results of lower gastrointestinal endoscopy: evaluation of $700 \mathrm{pa}-$ tients. Ulus Cerrahi Derg 2014; 30: 71-75.

2. Jia H, Wang L, Luo H, Yao S, Wang X, Zhang L, et. al. Difficult colonoscopy score identifies the difficult patients undergoing unsedated colonoscopy. BMC Gastroenterol 2015; 15: 46. [CrossRef]

3. Kim EJ, Kim YJ. Can body mass index predict the difficulty of colonoscopy? Clin Endosc 2016; 49: 106-107. [CrossRef]

4. Akere A, Otegbayo JA. Complete colonoscopy: impact of patients' demographics and anthropometry on caecal intubation time. BMJ Open Gastroenterol 2016; 7; 3. [CrossRef]

5. Jain D, Goyal A, Uribe J. Obesity and cecal intubation time. Clin Endosc 2016; 49: 187-190. [CrossRef]

6. Park HJ, Hong JH, Kim HS, Kim BR, Park SY, Jo KW, et. al. Predictive factors affecting cecal intubation failure in colonoscopy trainees. BMC Med Educ 2013; 19; 13: 5.

7. Nagata N, Sakamoto K, Arai T, Niikura R, Shimbo T, Shinozaki M, et. al. Predictors for cecal insertion time: the impact of abdominal visceral fat measured by computed tomography. Dis Colon Rectum 2014; 57: 1213-1219. [CrossRef]

8. Oh SY, Sohn Cl, Sung IK, Park DI, Kang MS, Yoo TW, et al. Factors affecting the technical difficulty of colonoscopy Hepatogastroenterology. 2007; 54: 1403-1406.

9. Anderson JC, Messina CR, Cohn W, Gottfried E, Ingber S, Bernstein $\mathrm{G}$, et al. Factors predictive of difficult colonoscopy. Gastrointest Endosc 2001; 54: 558-562. [CrossRef]

10. Krishnan P, Sofi AA, Dempsey R, Alaradi O, Nawras A. Body mass index predicts cecal insertion time: the higher, the better. Dig Endosc 2012; 24: 439-442. [CrossRef]

11. Khashab MA, Pickhardt PJ, Kim DH, Rex DK. Colorectal anatomy in adults at computed tomography colonography: normal distribution and the effect of age, sex, and body mass index. Endoscopy 2009; 41: 674-678. [CrossRef]

12. Bernstein C, Thorn M, Monsees K, Spell R, O'Connor JB. A prospective study of factors that determine cecal intubation time at colonoscopy. Gastrointest Endosc 2005; 61: 72-75. [CrossRef]

13. Wells CD, Heigh Rl, Sharma VK, Crowell MD, Gurudu SR, Leighton $\mathrm{JA}$, et al. Comparison of morning versus afternoon cecal intubation rates. BMC Gastroenterol 2007; 8; 7: 19. 